\title{
A Quantitative and a Qualitative Analysis of the Effect of Culture and Language on Arab Students' Response to Authentic Literature in English
}

\author{
Rahma I. Al-Mahrooqi \\ Sultan Qaboos University, Oman \\ Email: ralmahrooqi@yahoo.com
}

\begin{abstract}
Reading in a foreign language is laborious (Gorsuch \& Taguchi, 2008), involving interaction between bottom-up and top-down movement in the process of creating meaning. When reading authentic literature, students must grapple not only with the text's linguistic code but with the cultural code as well. Thus, language and culture can have profound effects on how students respond to and comprehend literature. The aim of this article, therefore, is to investigate the effect of these two factors on Arab student response to authentic American literature. Part of a major study, the article analyses quantitatively and qualitatively the responses of 23 female students while reading the American short story "I Want to Be Miss America". The analysis shows clearly how students' native culture and language come into play during the process of reading and understanding the text. Appreciating the effect of these factors offers literature teachers an insight into the sources of student difficulties with native literature. This in turn enhances their ability to negotiate meaning with their students and arrive at a plausible understanding of the target text. A further consequence is improved language acquisition by the students (Cheon, 2003).
\end{abstract}

Index Terms — native culture, foreign language, authentic literature, reader response

\section{INTRODUCTION}

The importance for the reading process of foreign language students' cultural orientation and background knowledge has long been recognized. Schema theory acknowledges reading's interactive nature (Rumelhart, 1981; Bensoussan, 1998), which involves a simultaneous interplay of bottom-up and top-down processes. Given problems around culture and background, therefore, it is not only a text's linguistic features that can prevent comprehension but content-related factors too. Research found that when textual information matches a reader's background knowledge, greater comprehension and recall take place (Carrell \& Eisterhold, 1988; Millan, 1999; Cheng, 2000). By contrast, mismatch between textual input and a reader's background knowledge creates difficulties, which also happens if incoming textual data is totally new. When recalling texts with information at odds with their pre-existing schema, readers tend to omit or distort the new input (Carrell, 1981). The conclusion seems to be that readers' personal prior knowledge is conditioned by their culture (Al-Seyabi, 2010; Millan, 1999; Al-Arfaj, 1996; Prichard, 1990). Put simply, texts containing familiar cultural content are easier to read and recall than, say, linguistically equivalent texts that contain unfamiliar information about a distant culture.

Reading the literature of a second or foreign language inevitably involves a struggle. As Urlab (2008, p. 26) puts it, "Reading literature across cultures is not only a reading process or a language process, but it is also influenced by the reader's cultural knowledge structures in the form of mental schemata". ESL/EFL readers experience difficulty because they naturally approach the literary text from a knowledge base within their own culture (Bouzenirh, 1991; Barnett, 1989). Scott (2001) holds that when students read texts with unfamiliar information they overcompensate for absent schema by reading slowly or by guessing, which of course may well cause a failure of comprehension (Nuttall, 1996; Scarcella \& Oxford, 1992).

When students lack an appropriate schema, the teacher must help them to build it in order to achieve a plausible interpretation of unfamiliar literary texts. It should be done interactively with both teachers and students negotiating meaning by sharing background knowledge and cultural orientation. This kind of dialogue, while generating meaning, improves language acquisition and critical thinking. However, EFL literature classes are often highly teacher-centered, with the teacher's voice dominant, a practice which, research has shown, deters language learning (Fisher; cited in Akers, 2009). Dialogue, on the other hand, empowers students allowing them to put into the foreign language personal experience, so that the language acquires life and real significance for them. If their own cultural experiences are explored alongside the text's, misunderstanding is avoided and literary appreciation fostered. This view is firmly 
supported by such reader response critics as Louise Rosenblatt, David Bleich, Wolfgang Iser and Stanley Fish (Harkin, 2005).

Rosenblatt sees literature reading as a transaction between reader and text in which the reader is actively involved in meaning making (Al-Mahrooqi, 2011). As the text evokes memories in the reader, the reader shapes meaning by checking the textual material against her background knowledge. Thus, a personal interpretation of the text is achieved. Rosenblatt thus affirms the validity of learner experience and its effect on literary text interpretation, making the unsurprising point that readers are influenced by past experience, current circumstance, regional origin, age, gender and upbringing, past and present reading.

Rosenblatt distinguishes two types of reading - efferent and aesthetic. Efferent reading is done simply to extract specific textual information. Aesthetic reading, however, focuses on personal involvement with text, which stirs personal feelings, attitudes, ideas and experiences (Arshed, 1998; Wang, 1999). All this gives the reader a literary experience that creates an intimate connection with the text and a measure of personal worth.

Because literature is aesthetic by nature and emerges from human experience, Rosenblatt calls for an aesthetic stance when engaging with it. And since literature can move readers by engaging their feelings, teachers should take advantage of this and allow students to respond accordingly (Probst, 1988; Lazar, 1990, 1996).

When adopting an aesthetic stance, readers' inclinations and experiences - their culture - find a place in which to be actualized (Probst, 1988). Readers, then, are not empty vessels; rather, they come to a text imbued with perceptions garnered from their own culture. When the text's culture resembles the reader's, the reader is likely to have an involving experience. Texts from a foreign culture might be difficult of access (hence a need for careful selection) and thus emotional involvement might well be thwarted. All texts contain multiple invisibilities: gaps, nuances about people, places and times, metaphors and vague references (Iser, 1980). These lacunae must be filled by the reader, who falls back on prior experience and searches his schema for information to render the text whole. The process prompts reader possession of the text (Mailloux, 1990; Selden, 1993).

Though applying reader response in the literature classroom has grown over the past twenty years, research has shown it happening largely with first-language reading and only rarely in ESL/EFL contexts (Al-Mahrooqi, 2011). This is unfortunate since, after all, this approach's principles are consonant with those of the communicative and studentcentered approaches, which both call for emphasis on learners and their experience (Carlisle, 2000).

The present study endeavors to show how present learners' culture is in their response to authentic literature, and what personal input and experiences are projected into the text - information that could be used by the literature teacher in negotiating meaning with learners to increase their comprehension and involvement in literature.

\section{THE STUDY}

This present study constitutes part of a larger exercise seeking to show how native culture influences affect responses to authentic literature in English. Twenty-three female students participated in reading the American short story "I Want to Be Miss America" by Julia Avarez. Its theme reflects the struggles of American minority women who try to survive in a society that places many demands and constraints on them. Beauty, color, and slimness are among the concerns of many young American women from diverse walks of life and ethnic backgrounds, and which the story's main characters share. Hailing from the Dominican Republic, and looking nothing like the participants in US beauty pageants, they nevertheless do everything to emulate their local counterparts and so acquire the American look. They are desperate to look beautiful in public and thus perhaps even assimilate into America's mainstream society and culture.

The researcher chose this story for Omani female students because she believed it would trigger responses that might highlight Omani cultural values different from those of American popular culture. For instance, while Omani women are encouraged to conceal their beauty, covering their body in public, except for face and hands, American popular culture emphasizes female freedom in terms of clothes and degree of bodily exposure.

\section{A. Quantitative Analysis of the Responses}

The story was divided into eight sections. Respondents wrote their responses immediately after reading each section in order to encourage detailed recording of their reactions and the avoidance of amnesia. After completing their responses, participants undertook a reflection task in which they were asked to reflect on the story they just read.

After collecting all responses, they were analyzed and tabulated according to Squire's 1964 response categories. These included:

1. Interpretational Responses. As the phrase suggests, this category includes attempts to arrive at the story's meaning by explaining events and characters' actions. The following sub-categories are included:

1.1 Text-oriented interpretation: Here the reader interprets textual information without attempting to hypothesize, predict, generalize, question or include didactic and religious comments.

1.2 Misinterpretation: This covers the failed interpretations the reader makes while attempting to comprehend the text.

1.3 Generalizations: Here, the reader speaks about what is in general natural, true or common among people and societies. 
1.4 Questioning: Readers sometimes question characters' motivation and actions although they are not really looking for answers. They might be questioning merely as a way of being cynical and sarcastic about characters' actions and motives.

1.5 Inquiry: Here, readers ask questions to which they actually need an answer. They might have missed a point in the story and seek clarification about it. Such inquiries might indicate confusion or a lack of overall comprehension of the story and its elements.

1.6 Hypothesizing and reasoning: Readers sometimes hypothesize about what is going on in the story. This might take the form of a statement such as "I think this is happening because of this or that". Also readers sometimes list reasons for why they think the way they do, citing incidents or events in the story to support their interpretation. Reasoning may also involve pinpointing contradictions and events in the story that are at odds with the social norms and customs of the cultural context or with the setting and time in which the story takes place.

1.7 Moral and personality judgments: Readers sometimes pass judgment on the virtue or intellect of character because of the way they behave.

1.8 Didactic comments: Here readers turn to codes of religion and custom to support their interpretations and judgments. In this type of response, readers privilege the values and principles they believe in.

1.9 Prediction: Here, based on previous cultural knowledge, readers anticipate what will happen next in the story.

There is a second table that includes all of Squire's remaining categories. The second table, therefore, includes the following:

2. Literal judgment: This means judging the work's artistic quality, language, style or characterization. It might simply describe it as "good" or "obscure".

3. Narrational responses: Responses in this category merely retell the story's events.

4. Associational responses. These are responses in which readers establish links between the events, places, ideas or characters in the story and counterparts from their own experience and background.

5. Self-involvement: Here readers associate the way characters feel or think with the way they feel or think.

6. Prescriptive judgment: These are responses in which readers prescribe a course of action for the characters, giving them advice or saying what they should or should not have done.

7. Miscellaneous: These responses do not belong to any of the previous categories.

Inter-rater reliability of quantitative analysis.

To ensure the reliability of response analysis and categorization, some responses were randomly selected and given to another rater familiar with Squire's categories and with whom the researcher met to discuss the meaning of all the categories, and especially the new subcategories. The second rater analyzed the responses and categorized them. The categorization was correlated with the researcher's, resulting in an inter-rater reliability coefficient of $r=.97$ for the interpretational responses and .92 for the other categories.

\section{B. Qualitative Analysis of Data}

In order to achieve a clear idea about how the participants' culture affected their responses, the data obtained from both the free response and reflection tasks was analyzed qualitatively. Best and Kahn (1998) suggest three steps for analyzing qualitative data - organizing it, describing it, and interpreting it. Hence, the researcher first organized responses according to the categories into which they fitted. Then she described and interpreted them, checking the extent to which such phenomena as religion or beliefs, customs and traditions, family roles and relationships and other cultural indicators were present and affected participants' understanding of and involvement in the story.

\section{RESULTS AND DISCUSSION}

As already mentioned, "I Want to be Miss America" was divided into eight sections and participants received one section at a time, responding to it without seeing the other sections. The responses obtained were analyzed according to the categories explained earlier and their distribution across these categories is presented in this section. Both quantitative and qualitative results are displayed in subsequent sections. The subcategories of the interpretational responses are displayed in Table 1.

TABLE 1:

TOTAL NUMBER OF INTERPRETATIONAL RESPONSES AND THE PERCENTAGE OF RESPONSES IN EVERY INTERPRETATIONAL SUBCATEGORY

\begin{tabular}{|l|l|}
\hline Category & Total number of responses and Percentages \\
\hline Total number of responses & $\mathbf{2 8 . 1 3}$ \\
\hline Textual Interpretation & $56.0 \%$ \\
\hline Misinterpretation & $20.1 \%$ \\
\hline Generalization & $7.5 \%$ \\
\hline Questioning & $1.8 \%$ \\
\hline Inquiry & $1.6 \%$ \\
\hline Hypotheses and Reasoning & $1.0 \%$ \\
\hline Moral Judgment & $3.3 \%$ \\
\hline Didactic Comments & $7.7 \%$ \\
\hline Prediction & $1.2 \%$ \\
\hline
\end{tabular}


From this table it is clear that the textual interpretation subcategory accounted for a much larger percentage of responses than the other subcategories. However, qualitatively, most responses in this section were not specific. They were, in fact, superficial and fluid. Some participants included just one or two sentences in response to a particular section. An example of a response to section two is the following: "I understood from this section that they were not in America before and that they hoped to go to it and live in it for a while. It is a special place." Some responses included a large number of sentences and suggested that the main theme concerned the four girls' struggle to fit into American popular culture. A response in section three is an example of this:

This section shows us how people in America are concerned about appearances. These girls want everybody to pay attention to them and their beauty. They live in a dilemma because they cannot accomplish all of these things. But they dream about realizing them which leads to a psychological conflict inside them which in turn leads to their inability to live in serenity and calm.

In many instances, while reading and responding, participants seemed uncertain about their understanding of what they read. Many qualified their responses with "maybe" or "I do not know what this means but I think...." Here is one example:

This family no longer feels homesick and has started to live its life in a normal way in America... They are Hispanic, but the teacher and their classmates in school call them Puerto Ricans. I do not know the meanings of these terms, but I guess these are used to refer to the places they come from.

Another participant wrote in response to section six, "I did not understand this section very well, but maybe it is about the family's opinion regarding the American beauty pageants...."

Some participants simply focused on what they knew best when responding. They might be having difficulty in understanding a certain section and all its major ideas, but understand one minor point not very central to the story. Such participants might take that point, amplify it, and make it the major thrust of her response to the whole section. The following response to section three is an example: "This section shows how to take care of the outward appearance of a person and that is by taking care of makeup, straightening hair and using face make up and so on." Section six of the story mentioned fleetingly something about the four girls being groomed to be dutiful wives, and the response of one participant to the whole section was:

I understood how preparations for married life are done and how this stage differs from the stages preceding it because married life has responsibilities and duties that married people are obliged to fulfill.

This response is clearly general, too fluid and detached from the main theme. It is apparent here how the participant's schema is in play. When participants' inadequate linguistic skills prevent comprehension, they fall back on their own reservoir of knowledge. Here, however, personal schema did not match up with the text's schema - hence interpretational fluidity.

Some participants understood the story well and thus produced responses that contained well-defined textual interpretation. The following excerpt comes from one such response:

Their desire to be similar to the Americans made them change the way they looked step by step to achieve what they aimed for. From this passage we can see how the mother does not agree with them in this. That is why they do it behind her back. It is apparent from the passage how dazzled they are with America, with everything in it and how affected they are with its customs. This made them copy things as though their own customs and traditions and looks with which they came to America were shameful or frightening or incomplete and as though everything American was complete, flawless and has nothing negative about it. This attitude makes some people completely abandon their religion, traditions and customs.

As is apparent here, some participants stressed the importance of preserving one's own religion and traditions because this is vital in their own culture. It was amazing to see how many participants included the same sentence when addressing this issue. This sentence - "A person who has no past has no future" - is a famous quote from a Sultan Qaboos speech to the Omani people. The participants must have come across it on countless occasions during their education for Oman holds a massive annual festival to celebrate its traditions and history.

The second subcategory that contained many responses was misinterpretations. In fact, $20 \%$ of all interpretations were misinterpretations caused by the participants' unfamiliarity with the story's cultural content, their inability to establish connections between events, their being misled by wrong associations, and their inability to grasp the intention of the author. Furthermore, vocabulary and structure were obstacles that added to the text's difficulty.

The vocabulary problem was exacerbated by the differences in culture, which must have caused wrong associations and thus misinterpretation. Many participants were unfamiliar with the idea of beauty contests, and those who knew about them had never read about them in English. Hence, either the idea was completely absent from the participants' schema or the relevant language was missing from their linguistic reservoir. And so some participants interpreted the contest as a "festival" that "the queen" attends, showing that, other problems apart, they were unfamiliar with the system of government in the United States. This was not surprising, since many people in Oman have little knowledge of politics.

In the story, the elected beauty queen walks along "the runway" and is met with the cheers of the attending fans. However, some participants misinterpreted the word "runway" thinking that it meant "road." One wrote: "The beautiful woman walks on the road and the looks of admiration follow her." The word "decade" was misread as "day" by one 
participant, who thus seriously misunderstood the plot's time frame. Instead of realizing that the girls had spent years in America, she wrote: "after spending three days in America, they still feel like strangers". And yet the narrator had described how the family moved to New York, how the four girls tried to adjust, and how they went to a school where their native country was not even known to the American students and teachers. One participant misunderstood "as for" in the following sentence from the story: "As for Miss America, we sisters kept our choices secret until the end." The participant thought "as for" meant "like" instead of "regarding and thus wrote: "Like Miss America, we had a small secret that we kept to the end". Another participant misinterpreted the word "cheap" in the following sentence: "But the dresses that we picked out made us look cheap, she [the mother] said, like bad, fat girls." Hence she wrote: "The mother implores her daughters to wear clothes that are more chic and expensive," which was totally at odds with the mother's disapproval of her daughters' choosing American clothes that made them look vulgar rather than the clothes associated with their native culture.

Participants seemed unable to understand sentence structures that were complex or unusual. The sentence "Mami did not even notice our Naired legs; she was too busy disapproving of other changes", appearing in the fourth section of the story, was interpreted simply as "The mother was so busy that she did not notice the changes that happened to her daughters." One participant interpreted the same sentence as "The mother did not care about the changes in her daughters." Still another offered a very confused account of the fourth section as a whole. She wrote:

In this section, the mother was so busy that she did not see what her daughters were doing. Her daughters were trying to copy American women in the way they dressed such as using the flower on the neck and other things of the Western clothing. The father too did not notice the changes his daughters were displaying. Most of the time, he would sit and repeat a song. He used to stop in New York whenever he heard girls singing that song.

Many misinterpretations of this section occurred. For example, the girls did not like to wear clothes that had flowers on the collar; their mother wanted them to wear dresses with flower prints and bows at the neck because this form of dress was the common one in their old country. The father did not stop to listen to girls singing; he sang to the girls walking by him in the streets of New York. Some participants misunderstood the actions of the father. One wrote: "the father was ashamed of his daughters' action", but the narrator actually says, "there will be a day when our father will hold his head high being proud of us." Yet of course, it was the four girls who felt embarrassed by their father's singing to women or girls passing by him in the streets of New York. One participant described the song as "sarcastic" when it was not. The participants' cultural view of a father figure as someone who is always the decent guide and role model for his children affected their interpretation.

Difficulty with both vocabulary and sentence structure made many participants misinterpret the following excerpt from section five:

I did not have a preferred feature, but I was often voted the cutest, though my oldest sister liked to tease me that I had that kind of looks that did not age well. Although she was only eleven months older than I was, she seemed years older and ages wiser.

Of this one participant wrote:

The narrator thinks that she does not have good judgment to decide which of the sisters was the most beautiful, but her sister who was only eleven months older was much wiser and more able to do that.

The mother's remark about "Americans believing in democracy even in looks" was understood to mean "American women believe in democracy more than looks."

Because many participants missed the story's theme, which was the four girls' struggle to fit into America, they misinterpreted many sentences. Three thought that the four girls wanted someday to be good wives and mothers. Another wrote: "The narrator wished in the last section that all women can find a way to look beautiful just like Barbie so that every girl can participate in the beauty contest." One participant missed the theme because she thought the narrator was 'a boy' not one of the four sisters. Clearly, linguistic problems and unfamiliarity with the story's culture produced all these misinterpretations.

Because of linguistic difficulties, participants could not establish connections between events or even between paragraphs in the same section. For example, section six has two paragraphs which are related because they talk about beauty contestants. In both the narrator compares her own and her sisters' upbringing and future expectations with those of the contestants. Then, she describes the reactions of her sisters and father to what they saw in the contest. About this one participant wrote:

I feel there is no connection between the first part and the second part. The only thing that I understand is that the first part discusses how a woman can be a wife, and the second part speaks about the women on the stage and what they wear. So I do not feel there is any connection between these two parts.

Because the total context of the story was lost on many participants, they read each section as a separate entity and thus fell into much misinterpretation.

To conclude this section, it is clear that the linguistic difficulties the participants faced in terms of vocabulary and structure inhibited their understanding of the story. And the unfamiliar topic seemed to exacerbate the linguistic problem.

Generalization responses ranked third following textual interpretations and misinterpretations. Since the story highlights the struggle of four teenagers to fit into a new society, the participants identified with what the adolescent 
girls were doing. Thus, almost all their generalizations were about all teenage girls and how all fathers and mothers react to their actions. An example is the following: "These are natural incidents for all girls. They all want to be beautiful or at least not to look starkly different from those around them." An example of a generalization about mothers is "All the mothers want to feel that their children appreciate them very much." As for fathers we find: "This reflects a reality because we find that fathers are always busy with their work while mothers are the ones who care more about the children." These generalizations reflect Omani culture and the roles it prescribes for both mothers and fathers.

The fact that the story's main characters were immigrants with a native culture similar in many ways to Arabic culture left participants feeling confident about generalizing, not just about teenagers, mothers and fathers, but also about how all immigrants try to assimilate into their new culture and how their assimilation comes at the cost of losing their identity. Furthermore, the fact that all participants had gone through adolescence and had probably felt similar concerns about their appearance at some point also facilitated their generalizing.

Having been teenagers, participants felt able to offer advice to all women and teenagers about how it is more important to improve and perfect their characters than their looks. Hence, a plethora of didactic comments $(7.7 \%$ of the total number of interpretational responses). Those who understood about beauty contests wanted to make moral comments about them, saying, for example, that they "demean the woman by making her body a commodity to be displayed without any respect in front of the eyes of spectators." Indeed, the story contained much material in which the participants' Omani moral code was broken. To illustrate, the four girls sought to change their looks using artificial means such as makeup; they did not listen to their mother's advice; they acted behind their mother's back; they were ashamed of their old country; and they competed with one another to see who was the most beautiful. Participants felt moved to contrast their own culture with its Western counterpart, where a woman's appearance is highly valued and celebrated. A growing tendency among Omani girls to search for ideal looks and participants' disagreement with this produced much didactic comment. Hence the following:

When we see world beauty queens... we say glory to God who divided sustenance for some people are beautiful, some are not so beautiful, and some are not beautiful at all. And we walk away with one conclusion that maybe we do not possess beauty such as these women, but beauty is not always the beauty of the face. The beauty of the soul is one of the most important things a person needs to possess and everybody has a feature that distinguishes him from others and that makes him beautiful.

Some didactic comments were very concise because participants cited a proverb or gnomic saying such as in "A person with no past has no present" or "Contentment is an everlasting treasure." All such comments reflected the norms of the participants' own culture and its values.

The categories following didactic comments included far fewer responses than those already discussed. Moral judgment responses accounted for only 3.3\% of responses. Moral judgments that did arise focused on the girls' frivolity, their lack of character, self-respect and self-esteem. They were not severe because seeking beauty was regarded as a natural stage through which teenage girls go.

Due to the story's narrative nature and the fact that its plot contained no climax or obscurity, there were few inquiry responses. Examples included queries about the meaning of the song the girls' father sang and about the word "Hispanic" because some participants did not know its meaning.

Questioning responses, in which the participants interrogated the motives or actions of characters, were few (1.8\%). This might be, again, because the story had no major climax and because participants were having difficulty with understanding it. For example, when the four girls wanted to shave their legs, one participant asked, "Why do they care about that? Who would notice their skin or legs anyway? Few people care about these things." Responding to the narrator's desire to look American, another participant asked, "Why isn't she content with her reality? Why does she aspire to something she cannot reach?" When, in the last section, the narrator discovers that she should never have been dissatisfied with the way she looked, one participant asked, "Why didn't she discover this earlier?" It is apparent from these examples that Omani culture is in play here. A woman's body is her own and nobody should have any business with it; also a woman had better accept her fate and be content with the way God has created her.

Responses around reasoning and prediction were the least numerous of all. What few responses emerged reflected the culture of the participants. They expected that the four girls would do something wrong due to their preoccupation with beauty. One participant wrote: "I expect that in the following sections the girls will break all the obstacles that prevent the woman from venturing outside her home. Later, disasters will follow because of neglecting and breaking free from traditions and customs." Another wrote: "Their beauty is fake, therefore, they will face a lot of problems." The idea of anticipating disaster after breaking custom is, of course, an import from the participants' native culture.

Having covered the results in the interpretation category, the following section displays results for the remaining six categories. Table 2 shows mean responses for each category. 
TABLE 2:

THE MEAN PERCENTAGE OF RESPONSES IN ALL THE CATEGORIES INCLUDING INTERPRETATION

\begin{tabular}{|l|l|l|l|l|}
\hline Category & Mean Percentage & Std. Deviation & Minimum & Maximum \\
\hline Interpretation & 55.32 & 19.36 & 20.00 & 100.00 \\
\hline Literal Judgment & 5.17 & 10.03 & .00 & 45.45 \\
\hline Narration & 28.47 & 19.34 & .00 & 62.96 \\
\hline Association & 7.64 & 17.05 & .00 & 80.00 \\
\hline Self-involvement & 1.80 & 3.97 & .00 & 15.91 \\
\hline Prescriptive Judgment & .32 & .92 & .00 & 3.70 \\
\hline Miscellaneous & 1.27 & 2.61 & .00 & 10.34 \\
\hline
\end{tabular}

As shown in the table, narrational responses come after interpretational ones, having a mean percentage of (28.47\%). When examining these responses, it becomes clear that many participants tended to focus on minor details without showing their connection to the major theme. Hence, for instance the focus on mentioning how the four girls Naired their legs, straightened their hair and so on, without saying why they did so or without connecting this to the girls' struggle to fit into their new culture. Whenever participants had difficulty with figuring out what was happening in the story, they resorted to either narrating fragmented details or to producing generalized interpretations that said little about the story and remained unsubstantiated by details or reasoning. In response to section one of the story, a participant wrote:

This story starts with the narrator talking about herself and her sisters. Then, she talks about her family while they were watching the annual Miss America festival. She started by describing all that happens in the festival from beginning to end. And she described the participants in the festival. This festival has no parallel in our customs and Islamic and Arabic traditions.

The last sentence was associational, but all the others simply comprised details without mention of how they were related to the major theme.

Some participants understood the story and produced comments that integrated all types of responses and connected them to the theme of the girls' struggle to become assimilated into American society. This can be shown from the following:

The struggle of people of color appears here again as it did in the previous story [The Abortion]. In this section, the sisters want to be like the American girls in beauty. However, their looks, their complexion prevent them from achieving that. They try hard to develop themselves in order to acquire even a little of the American beauty because it is a struggle in the American society....

Exceptionally, the participant here connected the attempts of the four sisters to improve their looks to the struggle of people of color to fit the standard American profile of beauty.

The mean percentage for associational responses was (7.64\%). In general they were very personal, specific, emotional and varied since the story talked about experiences that the participants could relate to at one level or another, personally or otherwise. They included personal associations, family associations, associations with teenage attitudes in Oman, associations with stories they had read or movies they had seen, associations with a celebrity, and associations with ideas held in the community. Some participants remembered how homesick they felt after leaving their village or town to live in university hostels.

When the narrator said that her teachers and classmates did not know where her native country was, one participant remembered visiting her relatives in another town where the neighbors did not know where her original town was located. When the narrator talked about her sisters and herself being groomed to be dutiful wives, some participants recalled the opposition of traditional Omani elders to the idea of women working outside the home. The difference in culture here did not prevent an awareness of similarities. It could be concluded, therefore, that whenever a story depicts experiences corresponding to those of the learners, learner experience will be evoked and utilized despite cultural difference.

Some personal associations were specifically related to this story. Participants recalled how they used to be concerned about their own looks and how they searched for fashionable clothes. Some used not to like their skin color. For example, one participant mentioned that she had met a group of Kuwaiti girls who, with very light complexions, wanted to use tanning cream in order to look like her, yet she at that time did not like her own darker skin color. Much comment was made on what is currently happening among young women who concern themselves more with appearance than with character. One participant related how an Egyptian beauty queen refused to accept an invitation to attend a contest in a certain country because it required contestants to wear indecent clothes. The name Marilyn Monroe reminded one participant of the movie "'M' is for Moon among Other Things", which she had watched and in which this film star was mentioned. The attempt by the four girls in the story to change the way they looked reminded one participant of Michael Jackson, the African American singer, who kept changing his looks because he was not satisfied with them.

Examining these associations, one can see how varied they are, an indication that the participants suffer from no knowledge deficiency, except in some areas around, say, some differences between their culture and the culture of the English language. 
Literal judgment responses had a mean percentage of $(5.17 \%)$. As far as quality is concerned, these responses disclosed the difficulty some participants were having with understanding the story. Among the words that were listed as new or difficult were gawk, chipmunk, Hispanic, preside, pom-poms, guinea pig, vacation spot, ex-cute, and exbeauty. Some of the listed words were strictly related to the American culture and had no equivalent in the Omani culture such as guinea pigs, pom-poms and even Hispanic and chipmunks. Sometimes participants tried to figure out the meaning of new words by relating them to old words they knew. An example of that is the participant who tried to figure out the meaning of the words ex-beauty and ex-cute by relating them to ex-husband and ex-wife.

A participant who had difficulty with pom-poms and Hispanic thought that understanding the story is dependent on knowledge of culture. As the participant put it, "There are words that I do not understand such as pom-poms and Hispanic. I think this story is intended for an American audience so it is obscure to those who do not know much about the American culture." Thus, vocabulary difficulty was made worse by the participants' unfamiliarity with the American culture. The participants who had difficulty with vocabulary regarded it as the reason for their inability to understand the theme of the story and for feeling that it was vague.

In addition to responses related to vocabulary, there were responses related to the descriptions included in the story. Some participants did not appreciate the fact that the story included much description. In the reflection task, two participants asserted that description was not necessary and that it served only to distract the reader. One participant thought that the description of the sisters in section five was too unimportant for her to write about in the response and so she sufficed herself to mention general ideas about the passage. Another participant had the opinion that "it was not necessary to mention the father, mother, and bed because they do not relate to the theme in anyway. This is what is discouraging in such stories. They mystify the reader and prevent him from understanding."

Some participants' inability to see the connection between events due to their fragmented understanding of the cultural context convinced them that the story was not coherent enough to be understood. Two participants regarded section six of the story as vague because they thought it was not coherent. The participants' failure to understand the connection between events and descriptions is obvious in this comment: "I did not understand anything of this section. I feel it is not coherent. Sometimes it talks about the girls; sometimes it talks about the father, and sometimes it talks about the duties of the wives and mothers." The paragraphs in section six were, in fact, coherent in terms of content and language. However, the participants' lack of familiarity with the content or the topic coupled with the absence of clearly stated linguistic cues prevented them from perceiving the existing connections between events and ideas and hence the coherence of the whole section. It is clear that the participants needed to see some clear linguistic clues to signal the connection between events and descriptions in order for them to understand better the text that was unfamiliar in terms of content and language. Thus, coherence and cohesion are necessary to facilitate understanding.

The participants who had understood the story commented that this was a good story, that the ideas were clear and that the chronological order of events made it flow smoothly despite difficulty with vocabulary.

The mean for Self-involvement responses in this story was $(1.80 \%)$. The participants had feelings for the four girls and their mother. They felt sad for, sympathetic with or disappointed in the four girls. They pitied them for wasting their time in frivolous things such as their looks. They were saddened when the girls forgot about their homeland quickly and were ashamed of telling the teacher and their classmates about the location of their home country lest they know it was a third world country. Concerning the mother, many participants identified with her because her perceptions were similar to those found in Omani culture. She represented all the traditional values that Omani women are brought up to believe in. Therefore, it was not strange to find participants who felt that the mother was interesting, dynamic, and enthusiastic.

It has to be noted here that self-involvement responses were not the only responses that indicated that the participants were engaged in the story. Among others, associational responses signify self- involvement too. The participants had many personal association responses, indicating the universality of human experience and emotions in spite of cultural differences.

Miscellaneous and prescriptive judgment responses were few. The mean percentages for these two categories were $1.27 \%$ and $.32 \%$ respectively.

The prescriptive judgment responses, although not many, demonstrate the influence of the participants' culture. The daughters were asked to listen to their mother's advice; the mother was asked to have a stronger, more strict relationship with her daughters; the four girls were asked to submit to their fate and be satisfied with how God created them, to keep the love of their homeland alive in their hearts, and to go back to their home country because they were having difficulty in America. These responses correspond to the didactic comments the participants mentioned in their responses, all of which reflected the participants' cultural and religious beliefs.

\section{CONCLUSION}

To conclude, there are a number of findings or observations that appear to be the most consistent and most important for the purposes of this research, which can tell us much about the reading process of foreign language learners. First, when the context of the story is unfamiliar and there is the additional complication of language, the readers' mental representation of the story will be incomplete and fragmented. The narrational responses in the story, "I Want to be Miss America" were made of isolated minor details that were not connected to the theme. When facing difficulty with 
comprehension, some participants, instead of focusing on narrating details, chose to write very general and fluid interpretations. Both fragmented narration and fluid and general interpretations are indications of having difficulty comprehending the whole picture of the story.

An implication of this finding is that it is important to find out how familiar a text's culture is to the students in order to foretell the problems they might face. This could be done through asking them for a response to the text or to an aspect in it. To build cultural knowledge, advanced organizers can be used so when students commence reading, they would already have an idea about the context. Using story grammar (Amer, 2006) can ease comprehension of literature as the analysis of the different aspects can focus students' attention on important aspects of the story.

Another observation is that participants can have very personal associations when reading about a foreign culture provided that the text has some similarity with the readers' experiences. A third observation is that coherence and cohesion of ideas and sentences as well as the logical or chronological progression or succession of events can facilitate comprehension especially if the story is written in a foreign language while lack of coherence can stymie comprehension of unfamiliar content even if the story is written in simple language.

Furthermore, familiarity with content enables readers to discern connections between ideas and to perceive their coherence even when cohesive devices are not abundantly used in the text. If the story lacks linguistic cues that connects events or indicate shifts in them, the readers get confused and mystified by the events even if the story is written in their first or native language. If culture unfamiliarity is added to style complexity, then the problem is doubled and a good degree of comprehension becomes quite impossible. The implication of this is that students' language proficiency levels have to be considered when choosing literary pieces for them. Literary pieces written in clear language should be introduced to beginners, and ones with more sophisticated language should be given at higher levels. Students should enjoy the literary experience rather than be frustrated at it due to language complexity.

\section{REFERENCES}

[1] Akers, A. (2009). Perceptions of talk, text, transactions, and technology: Preservice teachers, CMC, and reader response. Unpublished $\mathrm{PhD}$ dissertation. North Carolina State University, USA.

[2] Al-Arfaj, I. (1996). Factors causing reading difficulties for Saudi beginning students of English as a foreign language. Unpublished Ph. D dissertation. Michigan State University, USA.

[3] Al-Mahrooqi, R. (2011). The responses of native and non-native speakers of English to English short stories. The Arab World Journal, 2 (1), 122-140.

[4] Arshad, M. (1998). Malaysian student teachers' response to muticultural literature. Unpublished PhD dissertation, University of Pittsburgh, USA.

[5] Barnett, M. A. (1989). More than meets the eye: Foreign language reading: Theory and practice. Englewood Cliffs, New Jersey: Prentice Hall Regents.

[6] Bensoussan, M. (1998). Schema effects in EFL reading comprehension. Journal of Research in Reading, 21 (3), $213-227$.

[7] Bouzenirh, F. (1991). Linguistics, Literature and the Moroccan EFL Context. Proceedings of the Conference on Linguistics and English Literature in Maghreb Universities. Fez: Dhar El Mahraz Publications. 1996 "African Literature, Culture and the Moroccan University" Rabat : 14

[8] Carrell, P. L. (1981). Culture specific schemata in L2 comprehension. In R. Ore \& J. Haskell (Eds.), Selected papers from the ninth Illinois TESOL/BE annual convention, First Midwest TESOL Conference (pp. 123-132). Chicago: IL: TESOL/BE.

[9] Carrell, P. L. \& Eisterhold, J. C. (1988). Schema theory and ESL reading pedagogy. In P. L. J. Devine \& D. E. Eskey (Eds.). Interactive approaches to second language reading. Cambridge, MA: Cambridge University Press.

[10] Carlisle, A. (2000). Reading logs: an application of reader-response theory in ELT. ELT Journal, 54 (1), 12-19.

[11] Cheon, H. (2003). The viability of computer mediated communication in the Korean Secondary EFL Classroom. Asian EFL Journal, 5 (1). http://www.asian-efl-journal.com/march03.sub2.php. Retrieved on June 20, 2011.

[12] Gorsuch, G. \& Taguchi, E. (2008). Repeated reading for developing reading fluency and reading comprehension: The case of EFL learners in Vietnam. System, 36, 253-278.

[13] Harkin, P. (2005). The reception of reader response theory. College Composition and Communication, 56 (3), 410-425.

[14] Iser, W. (1980). Interaction between text and reader. In S. R. Suleiman \& I. Corsman (Eds.), The Reader in the text (pp. 237255). Princeton: Princeton University Press.

[15] Mailloux, S. (1990). The Turns in reader response Criticism. In C. Moran \& E. Penfield, (Eds.). Conversation: Contemporary critical theory and the teaching of literature. Urbana, Illinois: NCTE.

[16] Millan, A. (1999). Using cultural schemata as a mechanism for easing comprehension and increasing reading interest for Puerto Rican students of English as a second language. Unpublished PhD dissertation. University of Puerto Rico, Puerto Rico.

[17] Nuttall, C. (1996). Teaching reading skills in a foreign language. Chicago: Heinemann.

[18] Pritchard, R. (1990). The effect of cultural schemata on reading processing strategies. Reading Research Quarterly, 25, 273293.

[19] Probst, R. E. (1988, Jan.). Dialogue with Text. English Journal, 77(1), 32-37.

[20] Rumelhart, D. (1981). Schemata: The building blocks of cognition. In J. T. Gathrie (Ed.), Comprehension and teaching (pp. $3-$ 55). Newark, DE: International Reading Association.

[21] Scarcella, R. C. \& Oxford, R. L. (1992). The tapestry of language learning: The individual in the communicative classroom. Boston, MA: Hillsade, NJ: Lawrence Erlbaum Associates.

[22] Scott, N. (2001). Helping ESL students become better readers: Schema theory applications and limitations. The Internet TESOL Journal, 7, 11, November.

[23] Selden, R. \& Widdoeson, P. (1993). Contemporary literary theory: A reader's guide. Kentukcky: The University Press. 
[24] Squire, J. R. (1964). The Responses of Adolescents while Reading four Short Stories. NCTE Research Report No. 2. Champaign, Illinois.

[25] Urlaub, P. (2008). Reading comprehension and literary narrative: Towards a model of reading literature in the second language. Unpublished PhD dissertation. Stanford University, USA.

[26] Wang, Y. J. (1999). Reader-response in foreign language education: A study of Taiwanese EFL high school students' responses to short stories. Unpublished PhD dissertation, University of Pittsburgh, USA.

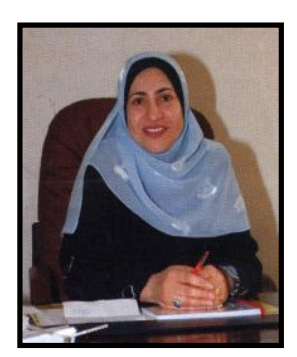

Rahma I. Al-Mahrooqi is from the Sultanate of Oman. She has a BA in English Education, an MA in English Curriculum and Teaching Methods from Sultan Qaboos University. She earned a Ph. D in English and Communications Education from the University of Pittsburgh, Pennsylvania, USA, in 2003. Currently, she is an Assistant Professor at the English Department of the College of Arts and Social Sciences, Sultan Qaboos University (SQU). Her research interests focus on English Language teaching, reading, literature, sociolinguistic issues, communication, intercultural and cross-cultural communication, the influence of culture on reading and communication. 